\title{
Analisis Keekonomian Pembangkit Listrik Tenaga Panas Bumi Kapasitas Kecil Sistem Siklus Uap
}

\author{
Nur Abdi Insani ${ }^{1}$ \\ ${ }^{1}$ Prodi Teknik Elektro UNPAM \\ Jln. Puspiptek Raya No 46 Buaran, Setu - Tangerang Selatan 15310 \\ nurabdi.insani@gmail.com
}

\begin{abstract}
ABSTRAK
PLTP merupakan energi yang bisa dikembangkan menjadi listrik. Sedangkan pada sektor ekonomi, kontribusi PLTP saat ini masih sangat kecil. Kebijakan harga maksimum pembelian listrik dari PLTP oleh PT PLN sebesar 12,6 cent US $\$ / \mathrm{kWh}$ untuk wilayah Indonesia bagian Barat. Kebijakan harga PLTP skala besar (> $30 \mathrm{MW}$ ) tetapi pada skala kecil $(<10 \mathrm{MW})$. Hasil perhitungan menunjukkan bahwa PLTP skala kecil bergantung pada kualitas sumber daya dan kondisi infrastrukturnya. Jadi, dapat diketahui diperlukan kebijakan baru yaitu feed in tariff.
\end{abstract}

Kata kunci: PLTP skala kecil, biaya pembangkitan

\section{ABSTRACT}

Analysis Of The Economy Of Small Capacity Geothermal Power Plants Dry Steam Cycle System. Geothermal Power Plants or commonly called PLTPs are energy that can be developed into energy. While in the economic sector, the contribution of PLTP is still very small.

The highest price policy for purchasing electricity from PLTP by PT PLN is 12.6 cents US \$ / kWh for the western part of Indonesia. Price policy for large-scale PLTP (>30 MW) while for small scale $(<10$ $M W$ ). The calculation results show that small-scale geothermal power plants depend on the quality of the resources and the condition of the infrastructure. So, it can be known that there is a need for a new policy in the form of a feed in tariff so that small-scale PLTPS can compete in the development of renewable energy for the long term.

Keyword: Small-scale PLTP, generation costs

\section{PENDAHULUAN}

$\mathrm{D}$ ari seluruh potensi panas bumi yang tersedia di Indonesia, hanya sekitar 4\% (1728 MW dari 28170 MW) saja yang sudah dimanfaatkan sebagai pembangkit tenaga listrik. Dalam setiap pembangunan PLTP tersebut, perlu diupayakan perhitungan dan yang maksimal.

\section{TEORI}

\section{Jenis-Jenis PLTP}

Mengubah energi panas dari cairan menjadi energi listrik sangat memungkinkan dengan menggunakan sistem konversi energi yaitu panas bumi (geothermal power system).
1. Siklus Uap Kering (Dry Steam)

Apabila cairan di mulut sumur berupa uap kering, maka uap dapat langsung dialrkan ke turbin, sehingga berputar dan mengkonversi energi gerak pada turbin menjadi listrik.

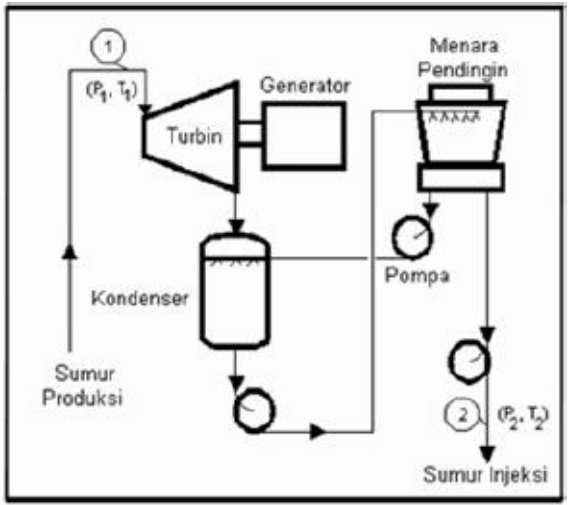

Gambar 1. Skema PLTP Uap Kering 
2. Siklus Uap Hasil Pemisahan satu kali (Single Flash Steam)

Siklus ini dgunakan jika cairan dimulut sumur dalam kondsi cairan jenuh. Cairan dialrkan ke sebuah flasher agar menguap. Tekanan flasher mempengaruhi banyaknya uap yang dihasikan, lalu dialirkan ke turbin.

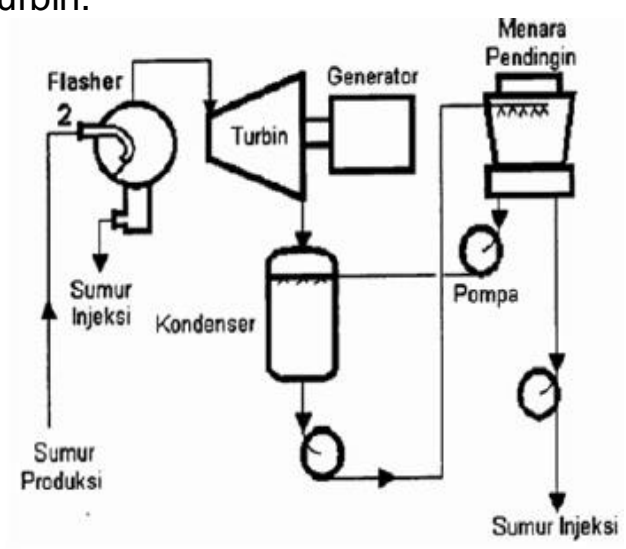

Gambar 2. Skema PLTP "Single Flash Steam"

3. Siklus Uap Hasil Pemisahan 2x (Double Flash Steam)

Digunakan 2 pemisah cairan yaitu separator \& flasher dan menggunakan 2 turbin, yaitu HPturbin (turbin tekanan tinggi) \& LPturbin (turbin tekanan rendah) dan disusun ganda.

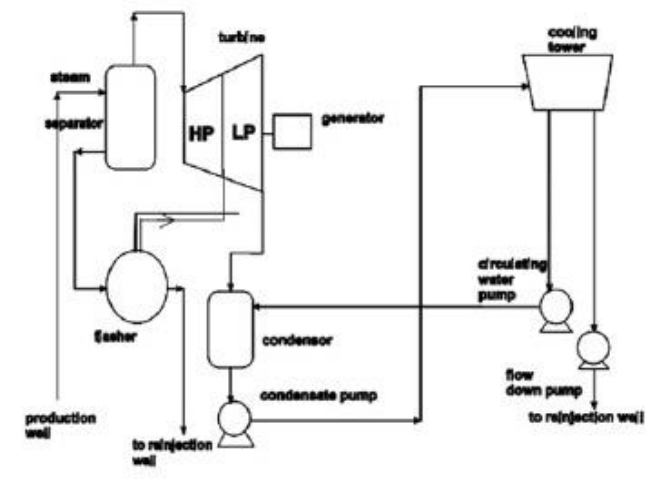

Gambar 3. Skema PLTP "Double Flash Steam"

4. Binary Cycle

Pada dasarnya cairan panas bumi yang digunakan untuk pembangkit listrk adalah cairan yang memiliki suhu $200^{\circ} \mathrm{C}$, namun cairan panas bumi suhu sedang (100 $200^{\circ} \mathrm{C}$ ) dapat digunakan dengan cara memanaskan cairan organik yang memiliki titik didih rendah, uapnya kemudian digunakan untuk menggerakan turbin.

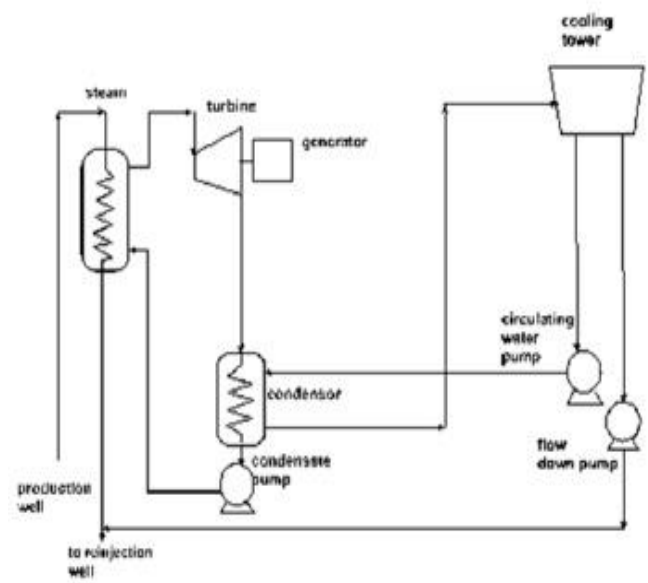

Gambar 4. skema PLTP "Binary Cycle"

\section{METODOLOGI}

\section{Sistem Siklus Uap Kering (Dry Steam)}

Sistem pembangkitnya lebih sederhana, hal ini dikarenakan sumber energi di dalam reservoir sudah berupa uap air (berfase gas) dan cenderung lebih bersih daripada jenis lainnya. Walaupun dilapangannya sangat jarang ditemukan, sumber energi panas bumi jenis ini adalah yang paling cocok untuk dijadikan pembangkit listrik.

Tabel 1. Perbandingan dari dasar sistem konversi energi panas bumi.

\begin{tabular}{|c|c|c|c|c|}
\hline $\begin{array}{c}\text { Jenis } \\
\text { pembangkit }\end{array}$ & $\begin{array}{c}\text { Temperatur } \\
\text { sumur, }{ }^{\circ} \mathrm{C}\end{array}$ & $\begin{array}{c}\text { Efisiesi } \\
\text { pemanfaatan, } \\
\%\end{array}$ & $\begin{array}{c}\text { Biaya pembangkit } \\
\text { dan komplek sitas }\end{array}$ & $\begin{array}{c}\text { Penggunaan } \\
\text { saat ini }\end{array}$ \\
\hline $\begin{array}{c}\text { Single- } \\
\text { flash }\end{array}$ & $200-260$ & $30-35$ & Sedang & $\begin{array}{c}\text { Tersebar } \\
\text { luas }\end{array}$ \\
\hline $\begin{array}{c}\text { Double- } \\
\text { flash }\end{array}$ & $240-320$ & $35-45$ & Sedang $\rightarrow$ Tinggi & $\begin{array}{c}\text { Tersebar } \\
\text { luas }\end{array}$ \\
\hline $\begin{array}{c}\text { Dry-steam } \\
\text { Basic }\end{array}$ & $180-300+$ & $50-65$ & Rendah $\rightarrow$ Sedamg & $\begin{array}{c}\text { Situs } \\
\text { Khusus }\end{array}$ \\
\hline Binary & $125-165$ & $25-45$ & Sedang $\rightarrow$ Tinggi & $\begin{array}{c}\text { Tersebar } \\
\text { luas }\end{array}$ \\
\hline
\end{tabular}

Dari tabel 1, dapat dilihat bahwa untuk PLTP jenis dry steam merupakan jenis PLTP yang sangat baik, dimana efisiensi pemanfaatannya merupakan yang paling baik dan paling murah biaya pembuatannya daripada jenis yang lainnya. 


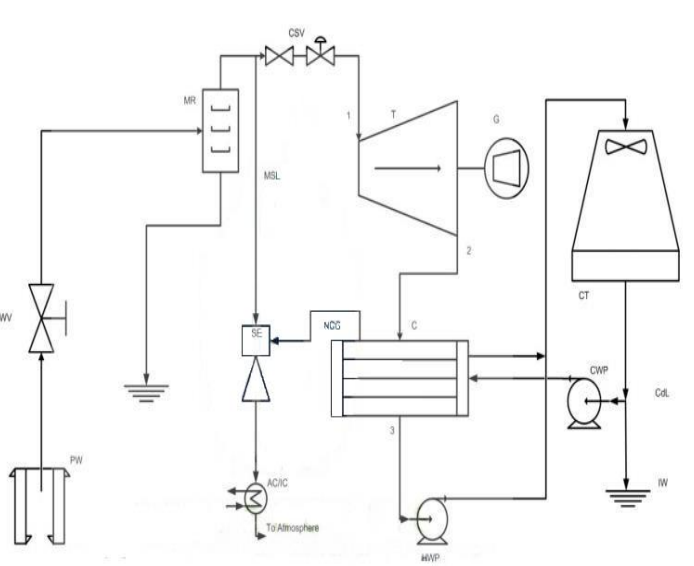

Gambar 5. Skema PLTP “dry steam” secara sederhana

Seperti digambarkan pada gambar 5 , siklus untuk PLTP berjenis drysteam tampak sederhana, dimana uap dari sumur produksi dialirkan langsung ke turbin untuk diubah energi panasnya ke energi mekanik dan diubah lagi ke energi listrik di generator. Uap dari turbin kembali dikondensasikan menjadi air kondensat di kondensor dimana air pendinginnya dari cooling tower dan kembali ke cooling tower lagi setelah dari kondensor.

\section{Sistem Uap Tunggal (Single Flash Steam)}

Gambar 6 menggambarkan skema aliran uap untuk PLTP single flash steam system dimana uap dari dalam bumi keluar dalam bentuk cairan dua fase (mixture steam-liquid). Oleh karena adanya penurunan tekanan (pressure drop) yang terjadi pada katup di sumur produksi dan cyclone separator, maka fase uap dan cairnya terpisah yang juga dipisahkan pada separator tadi. Penurunan tekanan pada enthalpy tetap disebut proses throttling. Dalam dunia PLTP, proses ini disebut proses flashing5, karena bukan hanya terjadi penurunan tekanan semata, akan tetapi proses ini membuat derajat kekeringan steam meningkat dan artinya menjadi lebih bersih dan aman untuk turbin.

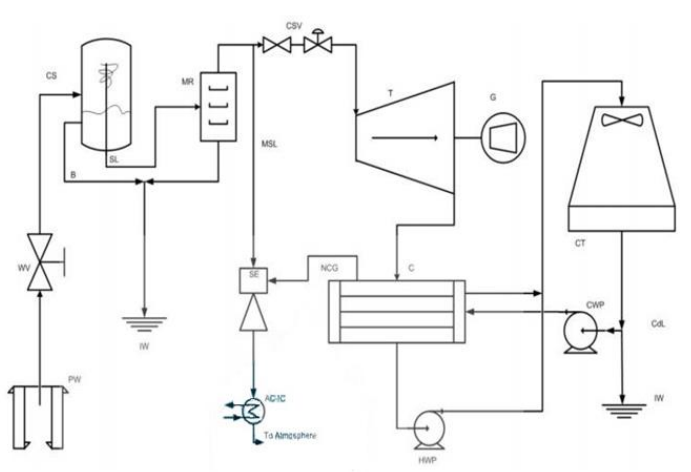

Gambar 6. Skematik PLTP Single Flash Steam Sistem secara sederhana

\section{Sistem Uap Ganda (Double Flash Steaml)}

Pembangkit listrik dengan tipe double flash steam system merupakan pengembangan dari pembangkit jenis single flash system. Skema proses untuk double flash steam system tidak jauh berbeda dari single flash steam system. Hanya ada penambahan flasher pada sisi keluaran separator yang berfungsi sebagai pemisah atau pengekstrak uap kembali dari brine dengan menggunakan prinsip yang hampir sama dengan separator.

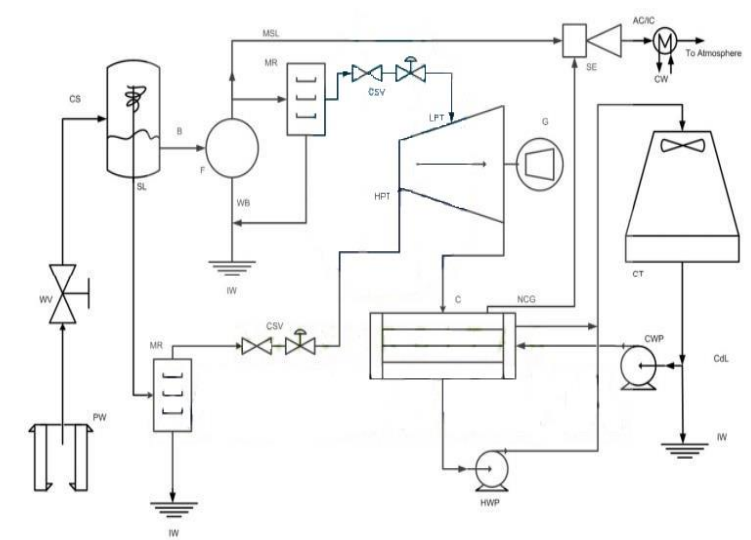

Gambar 7. Skematik PLTP Double Flash Steam System

\section{Perhitungan Biaya Pembangunan PLTP}

Dalam perhitungan keekonomian pembangunan PLTP diperlukan beberapa variabel input seperti nilai suku bunga, nilai penyusutan atau depresiasi, biaya total investasi, kapasitas pembangkit. 


\section{HASIL DAN PEMBAHASAN}

\section{Analisa Biaya Pembangkitan Panas Bumi}

Dalam memperhitung kanpenentuan harga listrik dengan sumber panas bumi, perlu memperhatikan hal-hal berikut:

1. Capital Investment Cost

Baya ini dperlukan untjk membangun pembangkt atau dalam proses eksplorassi titik-ttik uap panas bumii, dinyatakan dalam US $\$ / k W$.

2. Biaya Pembangkitan

(Power Generating Cost).

Biaya pembangkitan adalah yg berhbungan dengan investasii awal dalam membangun pembangkt listrik seperti, biaya bahan bakar dan operasional dan perawatan, diinyatakan dalam cent/kWh (1 centt $=1 / 100$ mta uang).

\section{Perhitungan Biaya Modal}

Tabel 2. Data pembangkit listrik tenaga panas bumi

\begin{tabular}{|c|c|c|c|}
\hline Data & \multicolumn{3}{|c|}{ Nilai } \\
\hline $\begin{array}{c}\text { Kapasitas } \\
\text { Terpasang }\end{array}$ & $5 \mathrm{MW}$ & $7 \mathrm{MW}$ & $10 \mathrm{MW}$ \\
\hline Umur Pembangkit & 30 Tahun & 30 Tahun & 30 Tahun \\
\hline Bahan Bakar & $\begin{array}{c}\text { Uap Panas } \\
\text { Bumi }\end{array}$ & $\begin{array}{c}\text { Uap Panas } \\
\text { Bumi }\end{array}$ & $\begin{array}{c}\text { Uap Panas } \\
\text { Bumi }\end{array}$ \\
\hline $\begin{array}{c}\text { Capital } \\
\text { Investment Cost }\end{array}$ & 15 Juta USD & $\begin{array}{c}\text { 18 Juta } \\
\text { USD }\end{array}$ & $\begin{array}{c}25 \text { Juta } \\
\text { USD }\end{array}$ \\
\hline
\end{tabular}

Secara umum biaya pembangunan dapat dilihat pada tabel 3 kapasitas $5 \mathrm{MW}$ dengan biaya investasi sebesar US\$15 juta, didapat sebesar US\$ 3.000 . Selanjutnya dengan menggunakan cara yang sama biaya pembangunan kapasitas $7 \mathrm{MW}$ dan 10MW.

Tabel 3. Biaya pembangunan pembangkit (Ps)

\begin{tabular}{|c|c|c|c|}
\hline $\begin{array}{c}\text { Kapasitas } \\
\text { Pembangkit } \\
(\mathrm{kW})\end{array}$ & & $\begin{array}{l}\text { iaya Total } \\
\text { Investasi }\end{array}$ & $\begin{array}{c}\text { Biaya } \\
\text { Pembangunan } \\
(\mathrm{Ps})(\mathrm{US} \$ / \mathrm{kW})\end{array}$ \\
\hline 5.000 & $\$$ & 15.000 .000 & 3.000 \\
\hline 7.000 & $\$$ & 18.000 .000 & 2.571 \\
\hline 10.000 & $\$$ & 25.000 .000 & 2.500 \\
\hline
\end{tabular}

Tabel 4. Biaya investasi

\begin{tabular}{|c|rr|rr|}
\hline $\begin{array}{c}\text { Kapasitas } \\
\text { Pembangkit } \\
(\mathrm{kW})\end{array}$ & $\begin{array}{c}\text { Biaya Investasi/ } \\
\text { Capital Cost } \\
\text { (CC) } \\
\text { (US\$/kWh) }\end{array}$ & $\begin{array}{r}\text { Biaya Investasi/ } \\
\text { Capital Cost } \\
\text { (CC) ( cent } \\
\text { US\$/kWh) }\end{array}$ \\
\hline 5.000 & $\$$ & 0,067 & $\$$ & 6,753 \\
\hline 7.000 & $\$$ & 0,058 & $\$$ & 5,773 \\
\hline 10.000 & $\$$ & 0,056 & $\$$ & 5,613 \\
\hline
\end{tabular}

\section{Biaya Bahan Bakar}

Harga panas bumi untuk PLTP adalah sebesar 1,50 US $\$ /$ Ton. Dengan konsumsi panas bumi diasumsikan sebesar 8,2 Ton/MWh.

Tabel 5. Perhitungan Biaya Bahan Bakar

\begin{tabular}{|l|c|}
\hline Perhitungan & Nilai \\
\hline Harga Panas Bumi (US\$/Ton) & 1,50 \\
\hline $\begin{array}{l}\text { Konsumsi Panas bumi } \\
\text { Ton/MWh }\end{array}$ & 8,20 \\
\hline $\begin{array}{l}\text { Konsumsi Panas bumi per } \\
\text { Tahun Ton/kW-tahun }\end{array}$ & 71,83 \\
\hline $\begin{array}{l}\text { Fuel Cost (CF) (cent } \\
\text { US\$/kWh) }\end{array}$ & 1,23 \\
\hline Fuel Cost (CF) (US\$/kWh) & 0,0123 \\
\hline
\end{tabular}

\section{Biaya Operasional dan Perawatan (O\&M)}

Tabel 6. O\&M berdasarkan kapasitas terpasang pada pembangkit

\begin{tabular}{|c|c|c|c|c|}
\hline \multirow{2}{*}{ Keterangan } & $\begin{array}{l}\text { Small } \\
\text { Plants }\end{array}$ & $\begin{array}{l}\text { Medium } \\
\text { Plants }\end{array}$ & \multicolumn{2}{|l|}{ Large Plants } \\
\hline & $<10 \mathrm{MW}$ & $\begin{array}{l}10- \\
30 \mathrm{MW}\end{array}$ & $>30 \mathrm{MW}$ & \\
\hline $\begin{array}{l}\text { Steam } \\
\text { Field }\end{array}$ & $\begin{array}{l}0,35-0,70 \\
\text { Cent } \\
\text { US\$/kWh }\end{array}$ & $\begin{array}{l}0,25-0,35 \\
\text { Cent } \\
\text { US } \$ / \mathrm{kWh}\end{array}$ & $\begin{array}{l}0,15-0,25 \\
\text { US\$/kWh }\end{array}$ & Cent \\
\hline $\begin{array}{c}\text { Power } \\
\text { Plant }\end{array}$ & $\begin{array}{l}0,45-0,70 \\
\text { Cent } \\
\text { US\$ } \$ \mathrm{kWh}\end{array}$ & $\begin{array}{l}0,35-0,45 \\
\text { Cent } \\
\text { US } \$ / \mathrm{kWh}\end{array}$ & $\begin{array}{l}0,25-0,45 \\
\text { US\$/kWh }\end{array}$ & Cent \\
\hline Total & $\begin{array}{l}0,80-1,40 \\
\text { Cent } \\
\text { US\$/kWh }\end{array}$ & $\begin{array}{l}0,60-0,80 \\
\text { Cent } \\
\text { US } \$ / \mathrm{kWh}\end{array}$ & $\begin{array}{l}0,40-0,70 \\
\text { US\$/kWh }\end{array}$ & Cent \\
\hline
\end{tabular}

Dengan melihat tabel 6 dan mengasumsikan kenaikan biaya perawatan sebanding dengan ukuran kapasitas yang terpasang dari pembangkit maka dapat dihitung nilai rata-rata dan diketahui bahwa biaya operasi dan perawatan kapasitas 5MW, 7MW, dan 10MW adalah 1.10 Cent US\$/kWh. 


\section{Perhitungan Biaya Pembangkitan Total PTLP}

Tabel dibawah ini merupakan biaya pembangkitan total adalah jumlah dari biaya modal, biaya O\&M, biaya bahan bakar, biaya operasional, dan biaya lingkungan.

Tabel 7. Biaya pembangunan Energi Listrik PLTP

\begin{tabular}{|l|c|c|c|}
\hline Perhitungan & \multicolumn{3}{|c|}{ Suku bunga 9\% } \\
\hline Kapasitas Pembangkit (kW) & 5.000 & 7.000 & 10.000 \\
\hline Biaya Pembangungan (US\$/kW) & 3.000 & 2.571 & 2.500 \\
\hline Umur Operasi (Tahun) & 30 & 30 & 30 \\
\hline Biaya Bahan Bakar (US\$/kWh) & 0,0123 & 0,0123 & 0,0123 \\
\hline Biaya O\&M (US\$/kWh) & 0,011 & 0,011 & 0,011 \\
\hline Biaya modal (US\$/kWh) & 0,067 & 0,058 & 0,056 \\
\hline Biaya Pembangkitan (US\$/kWh) & 0,091 & 0,081 & 0,079 \\
\hline Investasi (juta US\$) & 15 & 18 & 25 \\
\hline
\end{tabular}

\section{Pendapatan Per Tahun}

Untuk menentukan pendapatan per Tahun, maka harus diperhitungkan hasil produksi listrik selama satu tahun dengan pembangkitan $80 \%$ dari kapasitas maksimum pembangkit itu sendiri. Dengan melakukan asumsi untuk Maintenance Outage (MO) dan Forced Outage (FO) setiap tahunnya adalah 2 bulan maka dapat diketahui bahwa ketersediaan pembangkit dalam beroperasi adalah $83,34 \%$.

\section{Total Waktu Operasi $=$ Tersedia $x$ Hari $x$ Jam $x$ Faktor Kapasitas $=83,34 \% \times 365 \times 24 \times 80 \%$$$
=5.840,4672 \mathrm{Jam}
$$

Setelah mengetahui total waktu operasi pembangkit selama satu tahun maka dapat diketahui jumlah produksi per tahun dengan melihat pada tabel 8.

Produksi/Tahum = Kapasitas Terpasangx faktor kapasitas $x$ total waktu operasi

Tabel 8. Jumlah produksi per tahun

\begin{tabular}{|c|c|}
\hline $\begin{array}{c}\text { Kapasitas } \\
\text { Pembangkit }(\mathrm{kW})\end{array}$ & $\begin{array}{c}\text { Jumlah Produksi per Tahun } \\
\text { (kWh/tahun) }\end{array}$ \\
\hline 5.000 & 23.461 .869 \\
\hline 7.000 & 32.706 .616 \\
\hline 10.000 & 46.723 .738 \\
\hline
\end{tabular}

Dalam setiap pembangkitan energi listrik akan selalu ada pemakaian sendiri yang digunakan untuk lingkungan pembangkit itu sendiri. Pemakaian sendiri bisa diasumsikan sebesar $7 \%$ dari total kapasitas produksi pembangkit listrik.

Tabel 9. Jumlah pemakaian sendiri per tahun

\begin{tabular}{|c|c|c|}
\hline $\begin{array}{c}\text { Kapasitas } \\
\text { Pembangkit }(\mathrm{C}) \\
(\mathrm{kW})\end{array}$ & $\begin{array}{c}\text { Pemakaian } \\
\text { Sendiri }\end{array}$ & $\begin{array}{c}\text { Jumlah } \\
\text { Pemakaian } \\
\text { Sendiri } \\
(\mathrm{kWh} / \mathrm{tahun})\end{array}$ \\
\hline 5.000 & $7 \%$ & 1.635 .331 \\
\hline 7.000 & $7 \%$ & 2.289 .463 \\
\hline 10.000 & $7 \%$ & 3.270 .662 \\
\hline
\end{tabular}

Dari perhitungan produksi per tahun dan pemakaian sendiri kita bisa menghitung jumlah produksi jual per tahun.

Tabel 10. Produksi jual per tahun

\begin{tabular}{|c|c|}
\hline $\begin{array}{c}\text { Kapasitas } \\
\text { Pembangkit }(\mathrm{C}) \\
(\mathrm{kW})\end{array}$ & $\begin{array}{c}\text { Produksi Jual/Tahun } \\
(\mathrm{kWh} / \text { tahun })\end{array}$ \\
\hline 5.000 & 21.726 .538 \\
\hline 7.000 & 30.417 .153 \\
\hline 10.000 & 43.453 .076 \\
\hline
\end{tabular}

Dengan memasukan harga jual per kWh (KP) PLTP yang sudah ditetapkan oleh Pemerintah RI dalam Permen ESDM No. 17 Tahun 2014 maka dapat dihitung penghasilan produk listrik per tahun seperti pada tabel 11.

Tabel 11. Penghasilan produk listrik per tahun dalam US\$/kWh dan Rp/kWh

\begin{tabular}{|c|c|c|}
\hline $\begin{array}{c}\text { Kapasitas } \\
\text { Pembangkit } \\
\text { (C) (kW) }\end{array}$ & $\begin{array}{l}\text { Penghasilan } \\
\text { Produksi } \\
\text { Listrik per } \\
\text { Tahun (CIF) } \\
\text { (US } \$ \text { kWh) }\end{array}$ & $\begin{array}{c}\text { Penghasilan } \\
\text { Produksi Listrik per } \\
\text { Tahun (CIF) } \\
\text { (Rp/kWh) }\end{array}$ \\
\hline $\begin{array}{c}5.000(0,126 \\
\text { US\$) }\end{array}$ & 1.955 .388 & Rp 26.055.550.677 \\
\hline $\begin{array}{c}5.000(0,182 \\
\text { US\$) }\end{array}$ & $\$ \quad 2.737 .544$ & Rp 36.477.770.948 \\
\hline $\begin{array}{c}5.000(0,262 \\
\text { US\$) }\end{array}$ & $\$ \quad 3.954 .230$ & Rp 52.690.113.592 \\
\hline $\begin{array}{c}7.000(0,126 \\
\text { US\$) }\end{array}$ & $\$ \quad 2.737 .544$ & Rp 36.477 .770 .948 \\
\hline $\begin{array}{c}7.000(0,182 \\
\text { US\$) }\end{array}$ & 3.832 .561 & Rp 51.068.879.328 \\
\hline $\begin{array}{c}7.000(0,262 \\
\text { US\$) }\end{array}$ & 5.535 .922 & Rp 73.766.159.029 \\
\hline $\begin{array}{c}10.000 \\
(0,126 \text { US\$) }\end{array}$ & 3.910 .777 & Rp 52.111.101.355 \\
\hline $\begin{array}{c}10.000 \\
(0,182 \text { US\$) }\end{array}$ & 5.475 .088 & Rp 72.955.541.896 \\
\hline $\begin{array}{c}10.000 \\
(0,262 \text { US } \$)\end{array}$ & 7.908 .460 & Rp105.380.227.184 \\
\hline
\end{tabular}




\section{Analisa Nilai Sekarang (Net Present Value)}

Metode yg dapat digunakan untuk menilai gagasan proyek investasi adalah NPV, sehingga arus kas yang digunakan sudah dipotong dari biaya modal. Jika NPV nya positif, diartikan bahwa dana yang diinvestasi dpat menghasilkan PV arus kas yang lebih tnggi dari PV awal. Dapat disimpulkan, jika NPV nya lebih besar daripada nol maka gagasan proyek dapat diterima, namun jika lebih kecil daripada nol gagasan proyek dapat ditolak.

Tabel 12. Nilai NPV pada kapasitas pembangkit $5 \mathrm{MW}$ dengan asumsi suku bunga $9 \%$

\begin{tabular}{|c|c|c|}
\hline $\begin{array}{c}\text { Kapasitas } \\
\text { Pembangkit dan } \\
\text { Harga Jual }\end{array}$ & $\begin{array}{c}\text { Nilai Net } \\
\text { Present } \\
\text { Value (US\$) }\end{array}$ & $\begin{array}{c}\text { Nilai Net Present } \\
\text { Value (Rp) }\end{array}$ \\
\hline $5.000(0,126$ US\$) & $\begin{array}{c}\$ \\
1.575 .284\end{array}$ & Rp 20.990.655.638 \\
\hline $5.000(0,182$ US\$) & $\begin{array}{c}\$ \\
9.610 .877\end{array}$ & Rp128.064.941.062 \\
\hline $5.000(0,262$ US\$) & $\begin{array}{c}\$ \\
22.110 .690\end{array}$ & Rp294.624.940.609 \\
\hline $7.000(0,126$ US\$) & $\begin{array}{c}\$ \\
5.908 .138\end{array}$ & Rp 78.725.933.613 \\
\hline $7.000(0,182$ US\$) & $\begin{array}{c}\$ \\
17.157 .969\end{array}$ & Rp228.629.933.206 \\
\hline $7.000(0,262$ US\$) & $\begin{array}{c}\$ \\
34.657 .706\end{array}$ & Rp461.813.932.573 \\
\hline $10.000(0,126$ US\$) & $\begin{array}{c}\$ \\
9.321 .802\end{array}$ & Rp124.213.008.182 \\
\hline $10.000(0,182$ US\$) & $\begin{array}{c}\$ \\
25.392 .989\end{array}$ & Rp338.361.579.029 \\
\hline $10.000(0,262$ US\$) & $\begin{array}{c}\$ \\
50.392 .614\end{array}$ & Rp671.481.578.125 \\
\hline
\end{tabular}

\section{Analisa Tingkat Pengembalian Internal}

Tingkat pengembalian internal adalah tingkat bunga yang dapat menjadikan nilai $\mathrm{NPV}=$ nol, karena PV arus kas pada tingkat bunga tersebut sama dengan investasi awal. Dalam proyek ini faktor diskonto diasumsikan berkisar antara 6\% dan $12 \%$. Internal rate of return biasanya dibandingkan dengan Minimum attractive rate of return (MARR) adalah tingkat suku bunga pengembalian minimum yang menarik dimana nilai dari IRR akan dibandingkan dengan nilai MARR. Dalam proyek ini nilai MARR diasumsikan sebesar $20 \%$. Jika nilai IRR lebih besar dari pada nilai MARR maka proyek dikatakan layak, jika nilai IRR lebh kecil dari pada nilai MARR maka proyek dikatakan tidak layak.
Tabel 13. Nilai Internal rate of return

\begin{tabular}{|c|c|c|}
\hline $\begin{array}{c}\text { Kapasitas } \\
\text { Pembangkit dan } \\
\text { Harga Jual }\end{array}$ & $\begin{array}{c}\text { Nilai } \\
\text { MARR }\end{array}$ & Nilai IRR \\
\hline $5.000(0,126$ US\$) & $20 \%$ & $10,28106270 \%$ \\
\hline $5.000(0,182$ US\$) & $20 \%$ & $16,23318411 \%$ \\
\hline $5.000(0,262$ US\$) & $20 \%$ & $24,74084002 \%$ \\
\hline $7.000(0,126$ US\$) & $20 \%$ & $12,85007430 \%$ \\
\hline $7.000(0,182$ US\$) & $20 \%$ & $19,47965383 \%$ \\
\hline $7.000(0,262$ US\$) & $20 \%$ & $29,22666376 \%$ \\
\hline $10.000(0,126$ US\$) & $20 \%$ & $13,34557705 \%$ \\
\hline $10.000(0,182$ US\$) & $20 \%$ & $20,30077288 \%$ \\
\hline $10.000(0,262$ US\$) & $20 \%$ & $30,11921952 \%$ \\
\hline
\end{tabular}

\section{Payback Period}

Dalam investasi dibutuhkan sebuah metode perhitungan untuk mengetahui jangka waktu kembalinya modal yang sudah diinvestasikan dalam suatu proyek. Perhitungan inilah yang disebut dengan payback period atau periode uang kembali.

Tabel 14. Nilai Payback period

\begin{tabular}{|c|c|c|}
\hline $\begin{array}{c}\text { Kapasitas } \\
\text { Pembangkit dan } \\
\text { Harga Jual }\end{array}$ & $\begin{array}{c}\text { Payback } \\
\text { Period }\end{array}$ & $\begin{array}{c}\text { Payback } \\
\text { Period } \\
\text { (Tahun) }\end{array}$ \\
\hline $5.000(0,126$ US\$) & 8,671110178 & 9 \\
\hline $5.000(0,182$ US\$) & 5,479364413 & 6 \\
\hline $5.000(0,262$ US\$) & 3,793406132 & 4 \\
\hline $7.000(0,126$ US\$) & 7,575237296 & 8 \\
\hline $7.000(0,182$ US\$) & 5,696598068 & 6 \\
\hline $7.000(0,262$ US\$) & 3,25149097 & 4 \\
\hline $10.000(0,126$ US\$) & 7,392591815 & 8 \\
\hline $10.000(0,182$ US\$) & 4,566137011 & 5 \\
\hline $10.000(0,262$ US\$) & 3,161171777 & 4 \\
\hline
\end{tabular}

\section{KESIMPULAN}

1. Pembangunan PLTP tidak dapat dilakukan dalam sekala kecil dikarenakan nilai awal investasi yang sangat besar..

2. Diperlukan faktor-faktor yang lebih banyak agar perhitungan pembangunan PLTP dapat dikategorikan layak dari segi bisnis.

3. Pembangunan PLTP kapasitas 5MW pada harga jual 0,126 US\$ tidak dapat dikatakan layak dari segi bisnis 
dikarenakan nilai IRR lebih kecil dari pada MARR.

4. Pembangunan PLTP kapasitas 10MW pada harga jual 0,262 US\$ dapat dikatakan paling layak dari segi bisnis dikarenakan nilai IRR jauh lebih besar dari pada MARR dengan nilai $30,11921951 \%$.

5. Pembangunan pembangkit listrik tenaga panas bumi kapasitas 5MW hanya layak pada wilayah III atau Indonesia bagian Timur dengan harga jual 26,2 cent US\$ atau 0,262 US\$.

6. Pembangunan pembangkit listrik tenaga panas bumi kapasitas 7MW hanya layak pada wilayah III atau Indonesia bagian Timur dengan harga jual 26,2 cent US\$ atau 0,262 US\$.

7. Pembangunan pembangkit listrik tenaga panas bumi kapasitas 7MW hanya layak pada wilayah II dan III atau Indonesia bagian Tengah dan Timur dengan harga jual 18,2 cent US\$ atau 0,182 US\$ dan 26,2 cent US\$ atau 0,262 US\$.

\section{UCAPAN TERIMA KASIH}

Penyusunan penelitian ini melibatkan beberapa pihak, untuk itu saya ucapkan terima kasih kepada :

1. Bapak Prof. Dr. Ir. Hamzah Hilal, M.Sc

2. Bapak Syaiful Bakhri., S.T., M.Eng.Sc., Ph.D.

3. Bapak Seflahir Dinata, S.T., M.Pd.T.

4. Putri Pertiwi Wanajaya, ST, MT

\section{DAFTAR PUSTAKA}

[1] Ibrahim, Herman Darnel. "Geothermal Energy Development in Indonesia", Jakarta 2011.

[2] Departemen Energi dan Sumber Daya Mineral - Direktorat Jendral Mineral, Batu Bara dan Panas Bumi.

[3] Indonesia 2005 - 2025 Buku Putih, "Penelitian, Pengembangan dan Penerapan IImu Pengetahuan dan Teknologi Bisang Sumber Energi Baru dan Terbarukan untuk
Mendukung Keamanan Ketersediaan Energi Tahun 2025", Kementerian Negara Riset dan Teknologi, Jakarta 2006.

[4] Widyastuti, Arie. 2006. "Analisis Kelayakan Proyek Pembangkit Listrik Energi Panas Bumi Dengan Menggunakan Capital Budgeting Technique".

[5] Permana Indra, Bayu. "Studi Pembangunan Pembangunan Listrik PLT Panas Bumi"

[6] Firdaus, Alfa dan Ambiya Pietoyo. "Analisa Kelayakan Pembangunan Pembangkit Listrik Tenaga Panas Bumi Studi Kasus: Kamojang, Jawa Barat". Jurnal IImiah PASTI. Volume VI. Edisi 1.

[7] I. B. Fridleifsson, "Geothermal Energy for the Benefit of the People" Renewable and Sustainable Energy Reviews 5, 299 (2001)

[8] Nenny Saptadji (2009), Energi Panas Bumi (Geothermal Energy). Bandung, 2009.

[9] Peraturan Menteri Energi dan Sumber Daya Mineral. (2014). "Pembelian Tenaga Listrik Dari PLTP dan Uap Panas Bumi Untuk PLTP Oleh PT. Perusahaan Listrik Negara (PERSERO) Jakarta: 2014.

[10] Nainggolan, Handika Roberto dan Eddy Warman. "Studi Prakiraan Potensi Pembangkit Listrik Tenaga Panas Bumi di Pusuk Buhit Kelurahan Siogung-ogung Kabupaten samosir" Jurnal Singuda Ensikom. Volume 14. No. 38, Januari 2016.

[11] Sugiyono. Agus, "Keekonomian Pengembangan PLTP Skala Kecil". Seminar Nasional Teknik Kimia dan Musyawarah Nasional APTEKINDO 2012. Jakarta. 2015. 